University of South Florida

DIGITAL COMMONS

Digital Commons @ University of

@ UNIVERSITY OF SOUTH FLORIDA

South Florida

Mechanical Engineering Faculty Publications

Mechanical Engineering

$1-2020$

\title{
Adaptive Learning in a Numerical Methods Course for Engineers: Evaluation in Blended and Flipped Classrooms
}

Renee M. Clark

University of Pittsburgh

Autar Kaw

University of South Florida, kaw@usf.edu

Follow this and additional works at: https://digitalcommons.usf.edu/egr_facpub

\section{Scholar Commons Citation}

Clark, Renee M. and Kaw, Autar, "Adaptive Learning in a Numerical Methods Course for Engineers:

Evaluation in Blended and Flipped Classrooms" (2020). Mechanical Engineering Faculty Publications. 236.

https://digitalcommons.usf.edu/egr_facpub/236

This Article is brought to you for free and open access by the Mechanical Engineering at Digital Commons @ University of South Florida. It has been accepted for inclusion in Mechanical Engineering Faculty Publications by an authorized administrator of Digital Commons @ University of South Florida. For more information, please contact digitalcommons@usf.edu. 
Renee Clark ORCID iD: 0000-0002-1782-073X

\title{
Adaptive Learning in a Numerical Methods Course for Engineers: Evaluation in Blended and Flipped Classrooms
}

\author{
Renee M. Clark ${ }^{1}$, Autar Kaw ${ }^{2}$ \\ ${ }^{1}$ Department of Industrial Engineering and Engineering Education Research Center \\ Swanson School of Engineering, University of Pittsburgh \\ Pittsburgh, PA 15261 \\ rmclark@pitt.edu \\ ${ }^{2}$ Department of Mechanical Engineering \\ University of South Florida \\ Tampa, FL 33620 \\ kaw@usf.edu
}

\begin{abstract}
As use of adaptive learning technology in STEM courses gains traction, studies evaluating its impacts are important to undertake. Adaptive elearning platforms (AELP) provide personalized, flexible learning via monitoring of student progress and performance and subsequent provision of an individualized learning path containing various resources. In this study, adaptive technology was utilized in blended and flipped versions of a numerical methods course. A particular challenge with flipped instruction is pre-class preparation, in which videos with the same instruction for all students are often assigned. Therefore, to diversify pre-class learning, the instructor developed adaptive lessons via an NSF grant and rigorously assessed outcomes in this flipped class with adaptive learning. In addition, to fully evaluate the lessons and respond to calls from the literature, the lessons were implemented and evaluated in a blended version of the course, which was lecture-based with available online resources. Data from previous semesters of flipped and blended instruction (without adaptive learning were available), enabling a comparison of four instructional
\end{abstract}

This is the author manuscript accepted for publication and undergone full peer review but has not been through the copyediting, typesetting, pagination and proofreading process, which may lead to differences between this version and the Version of Record. Please cite this article as doi: 10.1002/cae.22175.

This article is protected by copyright. All rights reserved. 
methods. The comparisons consisted of direct assessment (i.e., exam questions) and affective assessment via a survey (i.e., perceptions of the classroom environment). An analysis was performed for students collectively and for underrepresented minority students in engineering. Focus groups enabled a comparison of student perspectives of using adaptive technology in blended versus flipped classrooms as well as by demographic. Upon combining these outcomes, including a notable Cohen's $d=0.34$ for open-ended-response performance, the flipped classroom with adaptive learning may be the best method for this STEM course.

Keywords: Adaptive learning, personalized learning, flipped classroom, blended classroom, numerical methods

\section{Introduction and Literature Review}

In prior research by the authors with the flipped classroom in a numerical methods course, a "one size fits all" non-personalized approach to the assigned preclass preparation activity was identified as a challenge in implementing flipped instruction [1]. To this end, the authors pursued a follow-up study that introduced adaptive software to flipped and blended implementations of this numerical methods course for engineering students. Adaptive learning is an online technique that can personalize learning among a large group of learners. Using learning algorithms, adaptive software is able to monitor student progress and adjust to individual needs given a student's interactions and performance with the software, resulting in a particular path or learning pace for a student. With the software, a student encounters various learning formats (e.g., videos, text, graphics, or simulations), assessments, and immediate feedback as he/she advances along a customized learning path, which may be a path in which mastery is being demonstrated or a path in which remediation is being provided [2].

The current article evaluates four methods for teaching this course: 1) flipped instruction, 2) blended instruction, 3) flipped instruction with adaptive software, and 4) blended instruction with adaptive software. With the blended instruction, class time was primarily dedicated to lecture, but with active-learning exercises infused throughout. With flipped instruction, students watched videos before class to prepare for in-class active learning. In the authors' previous study of flipped versus blended instruction (not involving any adaptive learning), small or negligible differences between the two methods as measured by exam scores were found [1].

Adaptive teaching and learning is a means to comprehensively address learning and educational needs by adapting instruction to individual students [3]. The long-time thought or belief has been that educational success is dependent on adapting, or changing, instruction to individual-student differences [3]. The adaptive theory is based on a cycle, in which instruction is initially adapted to students, with the goal of students eventually learning to adapt to instruction

This article is protected by copyright. All rights reserved. 
independently over time (i.e., be self-adapting or self-regulating) [3]. The traversal of this cycle is considered key for long-term development, or one's readiness to perform with various academic challenges [3]. This theoretical framework guided our work to address the challenges of pre-class preparation in the flipped classroom, in which all students are typically assigned the same instructional videos in a non-diversified fashion.

Various organizations have made calls for or are lending direct support to personalized learning. The National Academy of Engineering's call to "Advance Personalized Learning” was identified as one of the 14 Grand Challenges for Engineering in the 21st Century [4]. The Association of Public and Land-grant Universities (APLU) launched a three-year program in 2016 in conjunction with the Gates' Foundation in which seven member universities were selected to receive grants to adopt, implement, and scale the use of adaptive software in large, generaleducation, blended classes [5]. Besides striving to improve student success in these types of courses, the grant program also aimed to better support low-income, firstgeneration, and students of color [6].

Further, in its 2017 national technology plan (NETP) update, the U.S. Department of Education endorsed adaptive technology, and in particular adaptive assessment and testing as the next generation in assessment [7-8]. The 2018 Horizon Report -Higher Education Edition, a publication of the New Media Consortium and Educause, identified adaptive learning technology and artificial intelligence as the important technology developments likely to have an impact on higher education in the next two to three years [9].

However, multiple sources have stated that additional data, testing, studies, and results on adaptive learning are needed; therefore, the present article makes a needed contribution to the literature. For example, although Gartner ranked adaptive learning first on its list of strategic technologies impacting education in 2015, the research firm stated that "A lot of real-world testing remains" [10]. A Gates' Foundation program with higher education institutions - the Adaptive Learning Market Acceleration Program (ALMAP) - strongly called for future research in the area of blended classroom implementations of adaptive courseware, having generally found modest learning results with the adaptive implementations within its program [11]. Likewise, within K-12 public education, the research demonstrating the merits and effectiveness of adaptive learning has been reported to be limited [12]. After finding no significant differences in exam scores between adaptive and traditional learning, a recent journal article called for more research on adaptive learning [13]. Finally, in an article on adaptive learning in a high school math course, a lack of rigorous, quantitative evaluation of adaptive systems was identified, although students felt they could learn independently with this type of instructional approach [14]. Based on these calls for additional research on adaptive learning and the stated lack of evaluative studies in this area, it is proposed that the present study makes a noteworthy contribution to the academic literature.

Upon a review of the literature, a limited number of evaluative studies of mixed results were found. For example, there have been recent studies on adaptive tutorials for engineering mechanics that identify a reduction in failure rates, an increase in student satisfaction, and highly positive student comments about the

This article is protected by copyright. All rights reserved. 
tutorials [15-16]. In a recent article on the use of adaptive features within an elearning environment in a primary school setting, the adaptive features were associated with increased student effectiveness, which took into account both success rate with e-learning exercises and completion time [17]. However, in an article evaluating an adaptive online system in undergraduate anatomy and physiology across six schools, no significant overall improvement was found between sections using an adaptive platform versus those using online quiz questions. However, there was a significant effect for two schools individually, both of which were urban community colleges [18]. Interestingly, a community of practice among engineering mechanics instructors (several from the studies mentioned above) was pursued to drive adoption of these tutorials [19]. As evident, adaptive-learning outcomes may be somewhat mixed, although students identify advantages with adaptive learning. Given this, the following research questions in the present study aim to contribute to the empirical outcomes for adaptive learning in the STEM education literature by investigating and comparing blended and flipped instruction with and without adaptive technology.

RQ1: Are there performance differences on numerical methods multiple-choice problems upon comparing blended and flipped instruction with and without adaptive learning? Are differences evident for underrepresented minority students?

RQ2: Are there performance differences on numerical methods free-response problems upon comparing blended and flipped instruction with and without adaptive learning? Are differences evident for underrepresented minority students?

RQ3: Are there differences in the perceptions of the classroom environment in a numerical methods course upon comparing blended and flipped instruction with and without adaptive learning? What are students' perceptions of adaptive technology in blended vs. flipped classrooms, and do these perceptions differ by demographic groups?

\section{Methods}

\subsection{Classroom Implementation: Adaptive Learning Lessons and Instructional Methods}

Using an adaptive e-learning platform (AELP), lessons were initially developed by a seasoned instructor (i.e., second author) to enhance pre-class preparation in his flipped numerical methods course for engineers. He then later used them within a blended-learning version of the course for comparison and continued evaluation of adaptive learning. With these lessons, each student had a personalized learning path supported by multiple resources, including videos, text, quizzes with feedback, and simulations, all of which were combined into a single online location. Learning and performance were assessed in real time, enabling the adaptation of the software to the student's knowledge and skills as well as real-time feedback. Performance analytics from the software also provided subsequent feedback to the instructor for class monitoring, identifying topics for which the students may have been struggling (or excelling) as well as time spent on lessons by the students, as discussed further in a prior publication in this journal [20]. Each

This article is protected by copyright. All rights reserved. 
video was five to ten minutes in length, and ten percent (10\%) of the adaptive lesson grade was awarded for watching each video, with two videos maximum per lesson.

As stated, with adaptive learning technology, a student is taken down a particular learning path, depending on his/her performance on quiz questions, thereby adapting the learning to the learner's needs. For example, for the lesson on the Newton Raphson method of finding roots of nonlinear equations, students answered questions after the video. If a student answered incorrectly, a textual format of the video was presented for further instruction. If the student still failed to answer all questions, a pre-requisite lesson was then presented. A flowchart showing this progression is given in Figure 1.

Figure 1.Adaptive Learning Flowchart.

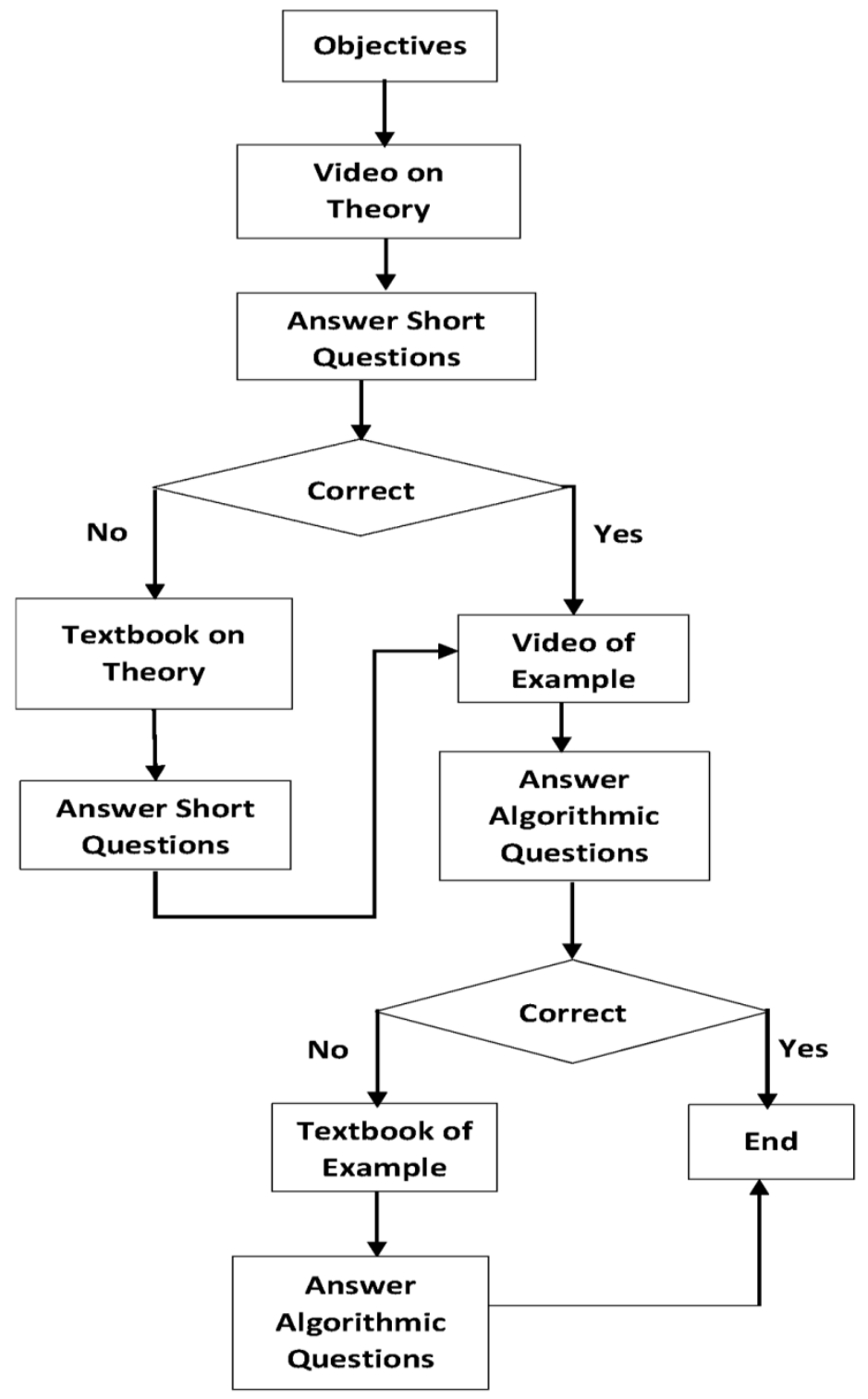

This article is protected by copyright. All rights reserved. 
With the present study, the flipped approach with adaptive learning was used and evaluated during two semesters (fall 2017 and spring 2018). Four numerical methods topics out of the eight covered in the course were available in the AELP for this exploratory implementation of adaptive learning - nonlinear equations, simultaneous linear equations, regression, and integration. Lessons for the course topics of scientific computing, differentiation, interpolation, and ordinary differential equations were not available for this preliminary implementation. With previous flipped classroom implementations without adaptive learning, students would watch the videos, read the online textbook, and take online quizzes prior to class. The flipped approach without adaptive learning was used during two semesters (fall semesters 2014 and 2015). Typical content and assessment elements of an adaptive lesson that was developed for this course are shown in Figure 2, using the LU Decomposition method as an example.

Figure 2. Typical Adaptive-Lesson Content.

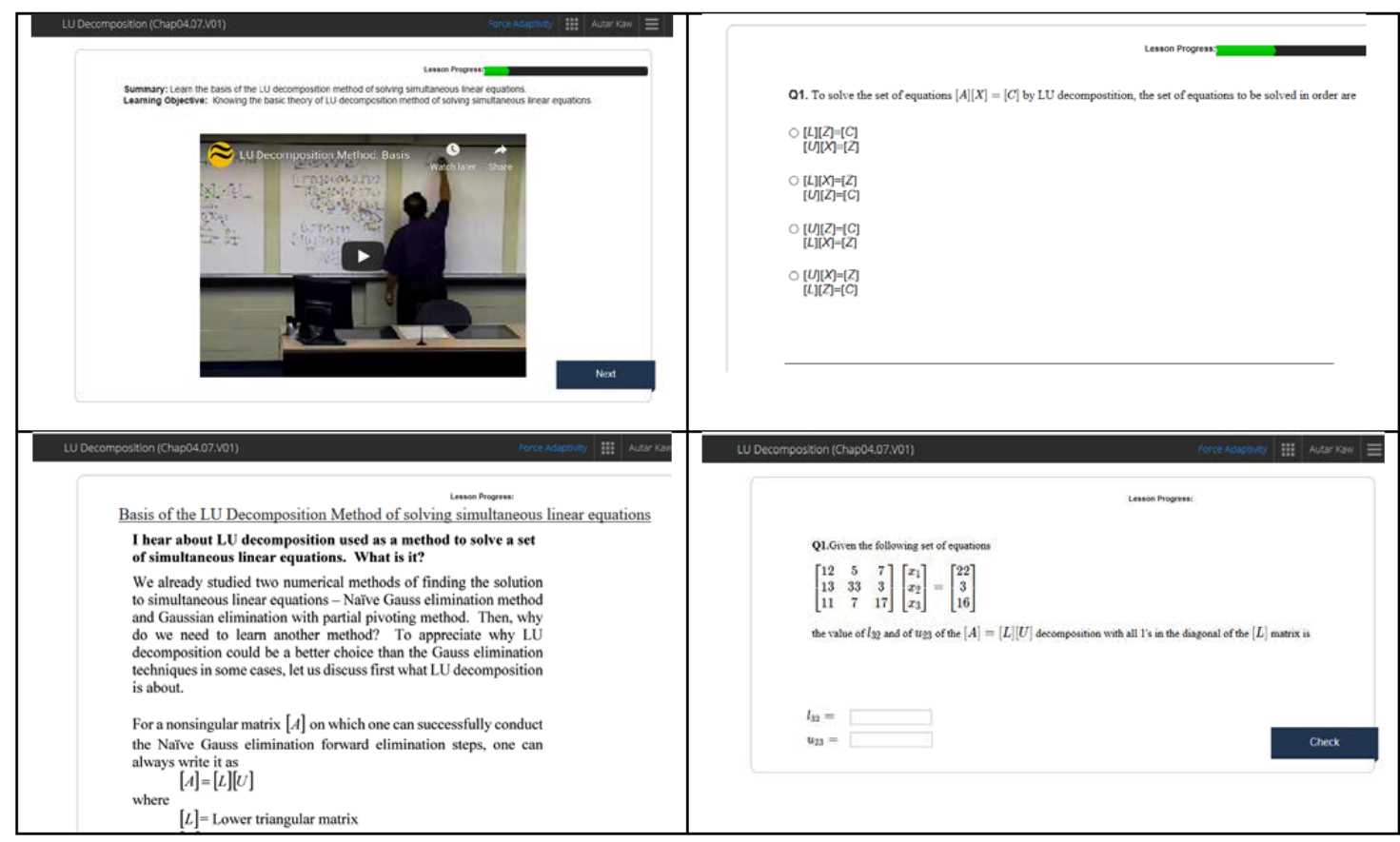

The blended instructional approach was used during three semesters (spring semesters 2014, 2015, and 2017). Class time was spent on lecturing of new content, clicker use, peer-to-peer learning, instructor discussion, and outlining of solutions to problems. Although students had access to the online videos, they were not expected to watch them before class, except those videos covering topics that were pre-requisites for the course. The ratio of lecture time to active-learning time was estimated to be 2:1 on average. The blended approach with adaptive learning was used and evaluated during the spring 2019 semester, and the same four AELP topics were available to students. With the blended classroom, the adaptive lessons were assigned after the material was covered in lecture, and students received course points for completing the lessons, as during the flipped version of the course.

This article is protected by copyright. All rights reserved. 


\subsection{Assessment Methods: Exam Comparisons and Student Focus Groups and Surveys}

An established assessment approach developed and utilized for prior NSF-funded research on blended versus flipped instruction was adopted for the present study with adaptive learning $[1,21]$. The assessment approach consisted of student focus groups and surveys, instructor interviews, and multiple-choice and free-response exam-question comparisons. Students' perspectives on adaptive technology were gathered and assessed via focus groups, and the classroom environment was assessed via survey. The multiple-choice and free-response comparisons from the final exam served to directly assess students' achievement associated with the various methods of instruction.

Final exam results could be compared across four instructional methods because the exam and instructor (i.e., second author) remained exactly the same for all semesters. In addition, to drive consistency and reliability in grading the freeresponse questions over time, a holistic rubric was used. The scale corresponded to the student's demonstration of his/her understanding of the problem as follows: 0 : no understanding; 1: little understanding with many requirements missing; 2 : partial understanding with most requirements completed; 3: considerable understanding with all requirements completed; and 4: complete understanding with all requirements completed. An analysis of covariance (ANCOVA), in which the student's GPA from his/her pre-requisite coursework served as the control, was used for the statistical comparisons of the exam results. For all students collectively as well as for the URM students, there was an adequate sample size of approximately $n \geq 30$ to run the parametric version of ANCOVA, as shown in Tables 3 and 4 [22]. Cohen's $d$ effect sizes for all pairs of means were calculated as a measure of the practical significance of the difference between the means [23$25]$. Both the $p$-value and effect size should be reported to depict the complete picture of significance, both statistical and practical significance, respectively [23, 25]. When calculating the effect sizes, the method without adaptive technology was considered the reference or control category, since adaptive technology was introduced to potentially enhance instruction. Further, the blended method was considered the reference when comparing it to the flipped methods.

To investigate the third research question, focus groups and a classroom environment survey were used. Specifically, Fraser's College and University Classroom Environment Inventory (CUCEI) [26], which measures seven psychosocial dimensions of the classroom, was administered anonymously. These seven dimensions, which are defined at the bottom of Table 5, are cohesiveness, individualization, innovation, involvement, personalization, satisfaction, and task orientation [26]. The CUCEI was chosen to study the classroom environment because several of its dimensions are typical goals of the flipped classroom, including student cohesiveness, individualization, innovation, involvement, and personalization. With adaptive learning, individualization, or individual or differential treatment according to ability or pace, is a key goal. A non-anonymous demographics survey enabled a collection of ethnic and racial data for investigating the achievement of underrepresented minority (URM) students with adaptive learning. The authors considered this to be a valuable investigation, as did Freeman et al. in their highly impactful 2014 paper on active learning [27]. Freeman et al.

This article is protected by copyright. All rights reserved. 
recommended additional "second-generation" research to test those types of active learning that may be best for certain populations, stating that URM students may benefit most from learning that is active [27].

Focus groups were conducted in the classrooms with adaptive learning (i.e., both flipped and blended versions) to examine students' perspectives on adaptive software and compare their perspectives in flipped versus blended environments. In addition, to examine the perspectives of different demographics, two focus groups per semester were conducted, one with each of the following groups: 1) the majority group in engineering (i.e., white males), and 2) the non-majority group (i.e., students who were "other than" white males. There were between four and seven students per focus group, for a total of 30 participants across the various focus groups. A sample of the focus group questions is shown in Table 1.

\section{Table 1.Focus Group Questions.}

The first author, who served as the assessment analyst for the project, and an upper-level undergraduate engineering student performed a content analysis (i.e., coding) of the focus group data [28]. The coding scheme had been developed earlier as part of this adaptive-technology research and is shown in Table 2 [29]. Using this coding scheme, each analyst independently coded the student responses, and they later discussed their codes before assigning final codes to each response, with multiple codes per response possible. Thus, the focus group data were doublecoded. Nonetheless, the first-time interrater reliability in the coding of the responses to the questions in Table 1 using this coding scheme was calculated as Cohen's $\kappa=0.77$, showing strong agreement beyond chance [22].

Additionally, for questions 1 through 3 in Table 1, the responses were coded in one of three possible ways -1) positive, 2) negative, or 3) mixed/neutral. Mixed/neutral responses typically consisted of a combination of positive and negative statements or contained statements that were neutral or unclear. For the coding of Q1-Q3 as positive, negative, or mixed, Cohen's $\kappa=0.81$, showing strong agreement. For Q4 from Table 1, the responses were also coded in one of the following three ways: 1) No difference, 2) Learning of AELP topics better/AELP preferred, or 3) Learning of AELP topics not better/AELP not preferred. For this coding, Cohen's $\kappa=0.87$ showing strong agreement.

Table 2.Coding Scheme for Focus Group Data.

Using the focus group data, differences in the percentages of codes from Table 2 for the flipped versus blended classrooms as well as for the two demographic groups were statistically tested using Fisher's Exact Test, which was used in lieu of a z-test of proportions because many of the numerator values were small [30]. The odds ratio (OR) was used to assess practical significance, as it provides a measure of effect size for binary variables [23]. OR values of 3 or higher are considered large, and values of between 2 and 3 are medium.

This article is protected by copyright. All rights reserved. 


\section{Results}

\subsection{Direct Assessment of Learning: Exam Comparisons}

To assess performance associated with each of the four instructional methods in a direct manner (i.e., the first and second research questions), multiple-choice and free-response results from the final exam were compared using an analysis of covariance. This was done for all participating students collectively and for underrepresented minority (URM) students, as shown in Table 3. The sample sizes available for each of the instructional methods were as follows: 188 for blended (i.e., blended non-adaptive, or BNA); 68 for blended with adaptive learning (BA); 88 for flipped (i.e., flipped non-adaptive, or FNA), and 146 for flipped with adaptive learning (FA). "Blended non-adaptive" and "flipped non-adaptive" refer to these instructional methods without the use of adaptive technology. Overall, there was demographic and exam data from $72 \%$ of the enrolled students for this analysis, with the following percentages for each instructional method: $67 \%$ for blended without adaptive technology (BNA), 75\% for flipped without adaptive technology (FNA), 74\% for blended with adaptive technology (BA), and 76\% for flipped with adaptive technology (FA).

Table 3.Multiple Choice Question Comparison: Four Methods.

For all students collectively as well as for URM students, the top performance percentage on the multiple-choice questions was associated with flipped non-adaptive instruction (FNA) (i.e., flipped instruction without adaptive learning), with percentages of $65.1 \%$ and $65.2 \%$, respectively. These are given by the covariate-adjusted mean percentages in Table 3 . The $p$-value from the ANCOVA comparing these four means for all students was $p=0.025$, which when adjusted for multiple comparisons using the Bonferroni adjustment, was still significant at $\alpha=0.05$ [31]. A $p$-value for an ANCOVA represents the same quantity as the $p$-value for any other statistical test, such as a t-test or ANOVA. Thus, since two tests were run (i.e., for all students and URM students), the $p$-value of 0.025 from the ANCOVA for all students was multiplied by a factor of two, as given in the " $p$ adj" column.

Thus, the four instructional methods were not all associated with the same mean achievement scores. An examination of the Cohen's $d$ pairwise effect sizes for all students collectively showed the largest effect size to be associated with flipped non-adaptive instruction (FNA) relative to blended instruction with adaptive learning (BA), with a near-medium effect size of $d=-0.47$. In this case, FNA (flipped without adaptive learning) was considered to be the reference or control category relative to blended with adaptive technology (BA), since adaptive technology was introduced to potentially enhance both the blended and flipped classrooms. There was also a notable effect size associated with flipped nonadaptive instruction (FNA) relative to flipped instruction with adaptive learning (FA) of $d=-0.32$. The analogous effect sizes for the URM population were $d=-0.40$ and $d=-0.41$, respectively. Thus, the multiple-choice results, both overall and for the URM students, did not favor adaptive learning in either the blended or flipped classrooms, in particular, relative to flipped instruction without adaptive technology (FNA). A comparison of flipped with adaptive (FA) and blended with

This article is protected by copyright. All rights reserved. 
adaptive (BA) teaching showed a small effect of $d=0.15$ in favor of FA for all students collectively. A limitation of these results are they are from one institution only and exam performance, and in particular multiple-choice performance, tends to be a short-term measure, as opposed to outcomes that may be apparent once students begin their careers.

However, the outcomes were different for the free-response results on the final exam (i.e., the second research question). For all students collectively, the most favourable results were associated with the flipped classroom with adaptive technology (FA), which had the highest adjusted achievement percentage of 44.4\%, as shown in Table 4. Conversely, the blended with adaptive approach (BA) was associated with the highest achievement percentage for the URM students. Although there were no significant differences in the mean percentages after applying Bonferroni's correction for multiple comparisons ( $p$ adj in Table 4), the effect sizes associated with adaptive learning (either with flipped or blended instruction) were small to medium in favor of adaptive learning for the freeresponse questions. The Cohen's $d$ effect size was $d=0.34$ when comparing flipped adaptive (FA) to flipped non-adaptive (FNA) for all students combined. For the URM students, the analogous effect size was $d=0.38$. Slightly higher were the effect sizes for blended instruction with adaptive (BA) relative to BNA and FNA for URM students, with $d=0.41$ and $d=0.48$, respectively. FA had a small effect size compared to BA for all students combined $(d=0.22)$. These outcomes are promising for adaptive learning in the flipped or blended classroom, in particular for URM students, with respect to more open-ended engineering problems.

Table 4.Free-Response Question Comparison: Four Methods.

An assessment of DFW rates, or the occurrence of D, F, or W (i.e., withdrawal) grades for the course, showed low values across the four instructional methods in the range of $4 \%-13 \%$. Blended with adaptive learning was associated with the lowest rate of $4 \%$, and flipped with adaptive was associated with the highest rate of $13 \%$. However, the assessment was not focused on DFW rates, as the final exam was considered to be the better tool for rigorously measuring cognitive and content achievement across the four methods. The final exam was objective, cumulative, and examined all levels of Bloom's taxonomy.

\subsection{Assessment of the Classroom Environment}

The College and University Classroom Environment Inventory (CUCEI) was used to compare the classroom environment among the four instructional methods (i.e., third research question). An overall CUCEI response rate of $65 \%$ of enrolled students was obtained, with the following response rates by instructional method: $66 \%$ for blended without adaptive learning (BNA), $66 \%$ for blended with adaptive (BA), 75\% for flipped without adaptive (FNA), and 56\% for flipped with adaptive (FA). Although the response rate was relatively lower for FA (being limited by those students willing to participate), it nonetheless constituted a majority of the enrolled students. The classroom-environment sample sizes for each method are given at the bottom of Table 5 .

This article is protected by copyright. All rights reserved. 
A multivariate analysis of variance (MANOVA) was used to compare the four instructional methods, given the seven outcome variables (i.e., dimensions) of the CUCEI classroom environment inventory, as depicted in Table 5 [22, 32].

Tamhane's T2 post-hoc tests, which do not assume equal variances, were used to identify the paired dimensions that significantly differed. Cohen's $d$ effect sizes for all pairs of means were calculated, as shown in Table 5.

The omnibus MANOVA test indicated a significant effect of the instructional method on the classroom environment $(p<0.0005)$. The classroom environment was rated highest for flipped with adaptive learning (FA) on four of the seven dimensions. The follow-up univariate ANOVA tests indicated a significant difference at $\alpha=0.05$ for three of these dimensions after correcting for multiple comparisons using the Bonferroni adjustment (i.e., multiplying each univariate $p$-value by 7). These three dimensions were Individualization, Personalization, and Task Orientation. The Individualization dimension measures individual or differential treatment according to ability or pace as well as student decision making power and is thus directly related to the goals of adaptive learning. This dimension was rated significantly higher with near-medium effect sizes for flipped with adaptive (FA) versus either flipped or blended instruction without adaptive learning, as shown in Table 5 by the Tamhane post-hoc values and Cohen's $d$ effect sizes of 0.43 and 0.48 , respectively. With the Individualization dimension, a comparison of FA versus BA resulted in a highly significant difference $(p<0.0005)$ and a large effect size $(d=0.85)$ in favour of the flipped classroom with adaptive learning (FA). Effect sizes of absolute value of 0.40 or higher were made bold in Table 5 .

For the Personalization dimension, which assesses interaction with the instructor and concern for student welfare, the flipped adaptive learning (FA) classroom was rated significantly higher than the blended adaptive (BA) classroom ( $p=0.001$ ), with a medium effect size of $d=0.68$. For this same dimension, the flipped with adaptive (FA) was also rated significantly higher than the flipped nonadaptive (FNA) classroom, with $p=0.001$ and medium $d=0.60$. For the Task Orientation dimension, which measures clarity and organization of assignments and activities, FA was rated significantly higher than FNA $(p=0.002)$ with a medium effect size of $d=0.53$. FA was also rated significantly higher than BA with a near-medium effect size of $d=0.47$. For the Involvement dimension, although significant differences were not found after Bonferroni's adjustment, there was a near-medium effect size of $d=0.41$ in favour of FA compared to BA. Thus, from an overall perspective, the flipped classroom with adaptive learning (FA) was the favoured classroom environment relative to the blended classroom with adaptive learning (BA) as well as the two types of classrooms without adaptive learning.

Table 5.Classroom Environment Comparison: Four Methods.

\subsection{Focus Groups: Evaluation of Adaptive Learning}

In investigating student perceptions of adaptive technology as part of the third research question, a series of focus groups were held. A total of 30 students participated in the various focus groups. The following section discusses the results of the content analysis of the focus group responses by both instructional method

This article is protected by copyright. All rights reserved. 
(i.e., blended vs. flipped) and demographic group (i.e., white males vs. other-thanwhite-males). Each of the four focus-group questions were analyzed individually. Question 1 is as follows:

\section{Question 1: Did the adaptive platform impact your learning or understanding more so than other methods for studying, learning, or reviewing content? Why do you feel this was the case?}

As shown in Table 6, the percentage of responses with predominantly positive sentiments was greater than the percentage with predominately negative sentiments, regardless of blended vs. flipped instruction, demonstrating the positive impact of the adaptive platform on learning in general. The same was true in Table 7 for the analysis by demographic group. The percentages of positive and negative responses were calculated by dividing the number of each type of response (i.e., positive or negative) by the number of focus group participants for the particular method or demographic group. For all focus group questions, since some responses did not address the particular question in a relevant way, not all responses could be coded as positive, negative, or mixed, and so the percentages do not necessarily add to $100 \%$.

Table 6. Focus Group Q1: AELP Learning Impact: Positive/Negative by Method

In Table 6, the percentage of responses from the blended classroom that were predominantly positive regarding the differentiated impact of the adaptive elearning platform (AELP) was higher than the percentage from the flipped classroom (60\% vs. 35\%), and this corresponded to a medium effect size of 2.79 based on the odds ratio $(O R)$, with the blended approach represented in the numerator. Conversely, there was a large effect size of $O R=3.00$ when comparing the corresponding negative percentages in Table 6, with the flipped classroom associated with $25 \%$ of responses with predominantly negative feelings to Q1 compared to $10 \%$ in the blended classroom.

As shown in Table 7, the percentage of non-majority (i.e., other-than-white-male) responses with predominantly positive responses to the differentiated impact of the AELP on learning was higher than the percentage of white male responses (50\% vs. 38\%), although this corresponded to a small effect size of $O R=1.67$. The analogous percentage of negative responses was higher for the white male students ( $25 \%$ vs. $14 \%$ ), with a medium effect of $O R=2.00$. The differences in these various positive and negative percentages discussed in Tables 6 and 7 were not significantly different based on Fisher’s Exact test [30].

Table 7: Focus Group Q1: AELP Learning Impact: Positive/Negative by Demographic

Based on a content analysis of the responses to question 1 as summarized in Table 8 , the positive impact of the adaptive platform on learning was most frequently associated with the MAT PREP category (Table 2), which encompasses lecture preparation, understanding of the material, increased exposure, and accountability. This was regardless of the demographic group or instructional method. The CONVENIENCE category was consistently associated with at least $20 \%$ of the responses to question 1 about the differentiated impact of the AELP on learning.

This article is protected by copyright. All rights reserved. 
CONVENIENCE was associated with all resources being in one online location, a guided approach, re-watching of videos on one's own time, and/or the re-doing of questions. The negative perceptions of the white males were most frequently associated with the NOT CLEAR code (25\%), which was assigned when the student indicated the AELP was not clear about what had been done wrong, why it was wrong, nor provide the solution. In the flipped classroom, the negative responses were also most frequently associated with NOT CLEAR (20\%) as well as ACCESS (20\%), which was assigned when there was a lack of desired access to lessons, questions, or other resources.

Table 8. Content Analysis of Focus Group Q1 on AELP Learning Impact

A non-majority (other-than-white-male) student from the blended classroom stated, "I saw a positive difference. If I was incorrect, I received automatic feedback and saw text, like for the derivations. The videos were repetitive relative to what was taught in class, actually verbatim. I liked the quizzes. I liked the adaptive platform." Another non-majority student from the flipped classroom stated, "I went over the material earlier and so would have to re-learn it later, which helped me. So, I had several times of being exposed to the same material...”

\section{Question 2: Discuss your satisfaction with the adaptive software and the reasons for it.}

Focus group question 2 investigated students' satisfaction with the AELP. The percentage of responses from the flipped classroom with predominantly positive feelings of satisfaction with the AELP was greater than the percentage from the blended classroom (30\% vs. 20\%) as shown in Table 9, although this difference was not significantly different and had a small effect size of $O R=1.71$. The same was true for the percentage of responses with predominantly negative feelings of satisfaction with the AELP. This percentage was also higher for the flipped classroom versus the blended classroom (35\% vs. 10\%), and in this case, the effect was large at $O R=4.85$.

Table 9. Focus Group Q2: AELP Satisfaction: Positive/Negative by Method

Based on the content analysis in Table 11, positive satisfaction in the flipped classroom was most-frequently associated with CONVENIENCE of the AELP (30\%), where all resources were available from one online location, a guided approach was provided, videos could be re-watched on one's own time, and questions could be re-done. Negative feelings of satisfaction in the flipped classroom were most frequently associated with ACCESS issues (40\%), although NOT CLEAR was again a prominent category both in the flipped (25\%) and blended (30\%) classrooms.

As shown in Table 10, the percentage of non-majority (other-than-white-male) students with predominantly positive responses related to their satisfaction with the AELP was much higher than the percentage of white males (43\% vs. $13 \%$ ), and this was associated with a large effect size of $O R=5.25$. This satisfaction was most frequently associated with CONVENIENCE (29\%), as shown in Table 11.

Table 10. Focus Group Q2: AELP Satisfaction: Positive/Negative by Demographic

This article is protected by copyright. All rights reserved. 
For the white males, with the higher percentage of predominantly negative responses (31\%), the lack of satisfaction was most frequently associated with ACCESS issues (63\%). NOT CLEAR was also a prevalent concern in Table 11, regardless of the group, always being associated with at least $20 \%$ of participants.

Table 11. Content Analysis of Focus Group Q2 on AELP Satisfaction

\section{Question 3: Did the adaptive learning software impact your engagement with the course material?}

The use of adaptive technology was associated with more predominantly positive responses regarding student engagement with course material in the flipped classroom (55\%) versus in the blended classroom (10\%), as shown in Table 12. This difference was significant based on Fisher's Exact test $(p=0.0235)$, and the effect size was large at $O R=11.00$.

Table 12. Focus Group Q3: AELP \& Engagement: Positive/Negative by Method

Relatively more white male responses (44\%) were predominantly positive regarding the impact of the AELP on their engagement, although this difference was not significant and the effect size was small at $O R=1.40$, as shown in Table 13 .

Table 13. Focus Group Q3: AELP \& Engagement: Positive/Negative by Demographic

In the flipped classroom, MAT PREP was the topic most frequently mentioned when engagement with course material was discussed (35\%; Table 14), and this is expected given the nature of the flipped classroom in which students are held accountable to prepare outside of class so as to fully engage in the active learning during class. Notice that the mention of MATPREP is relatively less frequent in the blended classroom, where students are not expected to complete the adaptive lessons before class (10\% in Table 14). CONVENIENCE was also frequently mentioned in the flipped classroom regarding engagement with content (20\%), and this is also an expected finding, as students can re-watch videos on the topics they may be struggling to independently grasp. For the participants in the blended classroom, the perceived WORKLOAD was the most frequent issue of concern, with participants often stating that the adaptive lessons were redundant or unnecessary since a lecture was given in class. Students were required to complete the associated lesson after the in-class lecture by the instructor in the blended classroom.

Table 14. Content Analysis of Focus Group Q3 on AELP \& Engagement

The white male responses most often discussed MAT PREP relative to their engagement (44\%). For example, a white-male student stated, "I was more engaged during class because I knew what was going on." However, the nonmajority (other-than-white-male) students most often discussed CONVENIENCE relative to their engagement. For example, one such student stated, "I have 5 classes/lectures all in one day, and so it's easy for me to doze off in class. The adaptive lessons are nice because I can do them on my own time, which has impacted my engagement positively."

This article is protected by copyright. All rights reserved. 
Question 4: Compare and contrast your learning of the topics covered by the adaptive platform versus those not covered by the platform.

Not unexpectedly, relatively more responses from the flipped (versus the blended) classroom indicated learning of the numerical methods topics covered in the AELP was better than learning of the topics not covered in the AELP (50\% vs. 30\% in Table 15), and the effect was medium at $O R=2.33$. In the flipped classroom, students were likely more dependent on the adaptive lessons for their learning of fundamental content, versus in the blended classroom where they received in-class lectures on all course topics.

Table 15. Focus Group Q4: Compare \& Contrast: Positive/Negative by Method

One of the flipped-classroom students stated, “...I feel less prepared for the upcoming exam versus earlier exams that covered the adaptive platform topics. I will have to spend time outside of class studying. I would have more confidence if ODEs had been covered in the adaptive platform. With the platform, I was 'walked through' the material, could see my grasp of the material, and received a reward, which was nice, but I didn't have this with ODEs." In Table 17 showing the content analysis of this question, MAT PREP was indeed the most-frequently mentioned category (45\%) in the flipped classroom, although it followed closely behind at $30 \%$ in the blended classroom. The CONVENIENCE of the adaptive platform was another frequent category for explaining students' perception of better learning of the AELP topics, stated in 30\% of flipped responses and $20 \%$ of blended responses. In Table 15, relatively more blended-class responses indicated that the learning of AELP topics was not better/preferred or that there was no difference compared to flipped-class responses, with WORKLOAD appearing in Table 17 as the most frequently mentioned category for blended participants. The effect size was large at $O R=8.14$. One such blended participant responded to this question as follows: "The adaptive platform material was a reiteration of class material and was not really necessary if one has the book. It was extra repetitive. The online quizzes in Canvas were better and less tedious. The platform would be really good for an online course. For an in-class course, the platform is tedious and not necessary. I did not get better answers via the adaptive platform."

In Table 16, 29\% of the non-majority (other-than-white-male) responses said the learning of AELP topics was not better/preferred, versus $0 \%$ of white-male responses. This difference was statistically significant based on Fisher's test ( $p=0.0365$ ). The most frequent theme associated with this for the former group was the WORKLOAD (29\%).

Table 16. Focus Group Q4: Compare \& Contrast: Positive/Negative by Demographic

Table 17. Content Analysis of Focus Group Q4 on Compare \& Contrast

\section{Discussion and Conclusions}

In this research, adaptive learning lessons were implemented and evaluated in blended and flipped versions of a numerical methods course for engineers. Adaptive lessons were anticipated to be particularly impactful in the flipped

This article is protected by copyright. All rights reserved. 
classroom due to their ability to individualize the pre-class, independent learning and preparation. Rigorous assessment to directly measure student learning with and without adaptive learning in both the blended and flipped classrooms was done. In addition, student perceptions of the impact of adaptive technology and of the classroom environment with these various teaching approaches were analyzed and presented in this paper.

The direct-assessment multiple-choice exam results did not favor adaptive learning in either the blended or flipped classrooms for all students collectively and for the URM students. However, for the free-response questions on the final exam, the most favorable results were associated with adaptive technology. Specifically, for all students combined, the flipped adaptive classroom had the best achievement percentage, and for the URM students specifically, the highest percentage was associated with the blended adaptive classroom. Although differences were not significant, the effect sizes were notable, with $d$ values in the range 0.34 to 0.48 , which were approaching medium size. Thus, the direct assessment outcomes show promise for adaptive learning with respect to the more unstructured engineering problems students may encounter. It may be the case that individualized learning is particularly beneficial or necessary with free-response unstructured problems, perhaps due to the self-regulated learning needed to effectively solve these types of problems requiring skills from the upper levels of Bloom's taxonomy.

Relative to the classroom environment, the flipped classroom with adaptive learning (FA) was rated highest by students on four of the seven dimensions, with three dimensions (i.e., Individualization, Personalization, and Task Orientation) showing significant differences and sizable (i.e., near-medium or higher) effect sizes between FA and the other methods. Given the elements of differentiated treatment and concern for student well-being embodied in the Individualization and Personalization dimensions, respectively, this outcome associated with adaptive technology in the flipped classroom is what we would expect.

The focus group results exhibited evidence of the positive impact of adaptive technology on student learning compared to other methods they may use for studying, learning, or reviewing. Specifically, in response to question 1 that asked about the differentiated impact of the adaptive e-learning platform (AELP) on learning, the percentage of responses with predominantly positive sentiments was greater than the percentage with predominately negative sentiments, regardless of blended vs. flipped instruction or the demographic group responding. This positive impact on learning was most frequently associated with lecture preparation, understanding of the material, increased exposure, and accountability.

In comparing adaptive technology in blended versus flipped classrooms, the flipped classroom was associated with more predominantly positive responses regarding student engagement (55\%) compared to the blended classroom (10\%), and these proportions were significantly different $(p=0.0235)$, with a large effect size $(O R=11.00)$. Also, relatively more responses from the flipped (versus blended) classroom indicated the learning of topics covered in the AELP was better than the learning of topics not covered in the AELP (50\% to 30\% in flip vs. blended classrooms), and this difference was of medium effect size $(O R=2.33)$. This is likely due to students in the flipped classroom being more dependent on the adaptive lessons for their independent, out-of-class learning. Lecture preparation

This article is protected by copyright. All rights reserved. 
and understanding of the material was indeed the most-frequently mentioned category (in $45 \%$ of responses) in the flipped classroom for this question. Interestingly, relatively more blended-class responses indicated that the learning of AELP topics was not better/preferred or that there was no difference, with WORKLOAD being the most frequently mentioned category for blended participants. Since the blended-course students received daily lectures, it appears they perceived the adaptive tutorials as less impactful or even unnecessary.

Interestingly, in comparing the majority to non-majority students (i.e., white males to other-than-white-males), the percentage of non-majority students with predominantly positive responses related to satisfaction with the AELP was much higher than the percentage of white males, and this was associated with a large effect size of $O R=5.25$ and the CONVENIENCE category.

Based on the instructor's assessment, students in the flipped classroom, in general, liked the adaptive platform, with many indicating to him they wanted all course topics to be covered by the platform. However, in the blended classroom, the adaptive platform content was not new to them (as they had seen it during lecture), and so it was less challenging to them. Consequently, he eliminated the requirement to minimally watch each video for two minutes. He reflected, "I am still thinking about how an adaptive lesson should be used in different settings.” Another lesson learned was that significant time was required on his part to program the platform, in addition to having the technical content ready for implementation. However, based on this study, adaptive learning holds promise for this course as well as potentially other STEM courses, particularly for the flipped classroom, given the favorable classroom environment, unstructured-problem outcomes, student comparison of their learning of numerical methods topics with the adaptive software (versus without it), and engagement with course material.

\section{Acknowledgment}

This material is based upon work supported partially by the National Science Foundation under Grant Number 1609637, and the Research for Undergraduates Program in the College of Engineering at the University of South Florida. The authors would like to thank

This article is protected by copyright. All rights reserved. 
Nicholas Abate and Brian Garver of the University of South Florida for their invaluable assistance. Any opinions, findings, and conclusions or recommendations expressed in this material are those of the authors and do not necessarily reflect the views of the National Science Foundation.

\section{Disclosure statement}

No potential conflict of interest was reported by the authors.

\section{References}

[1] Clark R, Kaw A, Lou Y, Scott A, Besterfield-Sacre M. Evaluating blended and flipped instruction in numerical methods at multiple engineering schools. Int $J$ Scholarsh Teach Learn, 2018;12(1), Article 11:1-16.

[2] Educause Learning Initiative. (2017) 7 Things You Should Know About...Adaptive Learning. Educause. https://ibrary.educause.edu//media/files/library/2017/1/eli7140.pdf. Accessed June 12, 2019.

[3] Corno L. On Teaching Adaptively. Edu Psychologist, 2008; 43(3):161-173.

[4] National Academy of Engineering. Advance Personalized Learning. http://www.engineeringchallenges.org/challenges/learning.aspx. Accessed Oct 7, 2017.

[5] Association of Public \& Land-Grant Universities. (2016). APLU Announces Awards for Seven Public Research Universities to Accelerate Use of Adaptive Courseware to Improve Undergraduate Education. http://www.aplu.org/newsand-media/News/aplu-selects-seven-public-research-universities-for--grant-toaccelerate-use-of-adaptive-courseware--to-improve-undergraduate-education . Accessed June 12, 2019.

[6] Association of Public \& Land-Grant Universities. (2018). APLU Releases First of its Kind Guide for Implementing Adaptive Courseware. Washington, DC. Available at: http://www.aplu.org/news-and-media/News/aplu-releases-first-ofits-kind-guide-for-implementing-adaptive-courseware. Accessed June 12, 2019.

[7] Lynch M. 5 things you should know about adaptive learning. Tech Edvocate. 2017; https://www.thetechedvocate.org/5-things-know-adaptive-learning/. Accessed June 12, 2019.

[8] 2017 National Education Technology Plan Update. US Dept of Education Office of Educational Technology. https://tech.ed.gov/files/2017/01/NETP17.pdf. Accessed June 12, 2019.

This article is protected by copyright. All rights reserved. 
[9] 2018

NMC

Horizon

Report.

https://library.educause.edu/resources/2018/8/2018-nmc-horizon-report.

Accessed June 12, 2019.

[10] Schaffhauser D. Adaptive learning tops strategic tech list for education. Campus

Technol. https://campustechnology.com/articles/2015/03/03/adaptivity-tops-gartner-edstrategic-tech-list.aspx, 2015. Accessed June 12, 2019.

[11] Yarnall L, Means, B, Wetzel, T. Lessons learned from early implementations of adaptive courseware. SRI Education; 2016: ES-i-ES-vi.

[12] Kronk H. What North Carolina got right about personalized learning, 2018. https://news.elearninginside.com/what-north-carolina-got-right-aboutpersonalized-learning/. Accessed June 12, 2019.

[13] Murray M, Pérez, J. Informing and performing: A study comparing adaptive learning to traditional learning. Inf Sci: Int J Emerg Transdiscipl, 2015;18:111-125.

[14] Özyurt O, Özyurt H, Baki A, Guven, B. Integration into mathematics classrooms of an adaptive and intelligent individualized e-learning environment: Implementation and evaluation of UZWEBMAT. Comput Hum Behav, 2013;29:726-738.

[15] Prusty G, Russell C. Engaging students in learning threshold concepts in engineering mechanics: Adaptive eLearning tutorials. In Proceedings of the International Conference on Engineering Education, 2011 Aug; Belfast, Northern Ireland, (p. 1-10).

[16] Prusty G, Russell C, Ford R, et al. Adaptive tutorials to target threshold concepts in mechanics - a community of practice approach. In Proceedings of the Australasian Association for Engineering Education Conference, 2011 Dec; Fremantle, Western Australia.

[17] Hubalovsky S, Hubalovska M., Musilek, M. Assessment of the influence of adaptive e-learning on learning effectiveness or primary school pupils. Comput Hum Behav, 2019; 92:691-705.

[18] Griff E, Matter, S. Evaluation of an adaptive online learning system. British J Edu Tech, 2013;44(1):170-176.

[19] Ben-Naim D, Prusty B. Towards a community of practice concerning the use of adaptive tutorials in engineering mechanics. In Proceedings of the 21st Annual Conference for the Australasian Association for Engineering Education. 2010 (p. 435-440).

[20] Kaw A, Clark R, Delgado E, Abate N. Analyzing the Use of Adaptive Learning in a Flipped Classroom for Preclass Learning. Comput Appl Eng Edu, 2019; 27(3):663-678; DOI 10.1002/cae.22106.

This article is protected by copyright. All rights reserved. 
[21] Clark R, Kaw A, Besterfield-Sacre M. Comparing the effectiveness of blended, semi-flipped, and flipped formats in an engineering numerical methods course. Adv Eng Edu, 2016;5(3).

[22] Norusis M. SPSS 14.0 Statistical Procedures Companion, Upper Saddle River, NJ: Prentice Hall; 2005. p. 183, 545-549,563-567.

[23] Sullivan G, Feinn R. Using effect size-or why the $p$ value is not enough. $J$ Grad Med Edu, 2012;4(3):279-282.

[24] Durlak J. How to select, calculate, and interpret effect sizes. J Pediatr Psychol, 2009;34(9):917-928.

[25] Kotrlik J, Williams H, Jabor M. Reporting and interpreting effect size in quantitative agricultural education research. J Agric Edu, 2011;52(1):132-142.

[26] Fraser B, Treagust D. Validity and use of an instrument for assessing classroom psychosocial environment in higher education. High Edu, 1986;15:37-57.

[27] Freeman S, Eddy S, McDonough M, Smith M, Okoroafor N, Jordt H, Wenderoth M. Active learning increases student performance in science, engineering, and mathematics. Proc Nat Academy Sci, 2014; 111(23): 1-6.

[28] Neuendorf K. The Content Analysis Guidebook, Thousand Oaks, CA: Sage Publications; 2002.

[29] Clark R, Kaw A. Benefits of adaptive lessons for pre-class preparation in a flipped numerical methods course. Intl J Math Edu Sci \& Tech, 2019; DOI 10.1080/0020739X.2019.1617439.

[30] Agresti A, Finlay B. Statistical Methods for the Social Sciences, Upper Saddle River, NJ: Prentice Hall; 1997. p 224.

[31] Perneger T. What's wrong with Bonferroni adjustments. BMJ, 1998;316:1236-1238.

[32] Field A. Discovering Statistics using SPSS, London: Sage; 2005. p. 571618.

Table 1.Focus Group Questions.

1) Did the adaptive platform impact your learning or understanding more so than other methods (that you use) for studying, learning, or reviewing content? Why do you feel this was the case?

2) Discuss your satisfaction with the adaptive software and reasons for it.

3) Did the adaptive software impact your engagement or interest with the course material?

This article is protected by copyright. All rights reserved. 
4) Compare and contrast your learning of the topics covered by the adaptive platform versus those (topics) not covered by the platform.

Table 2.Coding Scheme for Focus Group Data.

\section{CATEgory DEsCRIPTION/DEFINITION}

CODE

\section{Benefits/Positive}

Adaptive platform videos assist with preparing for lecture and/or understanding or learning the material, including increasing the exposure; platform assists in driving accountability with the videos or material in general

Quiz or questions included alongside lecture; able to confirm, reinforce, or gain understanding via the questions, including via feedback

QUIZ QUES

Adaptive platform provides convenience, tailoring, simplicity, and/or multiple resources. Examples - all resources available from the same website; can do according to one's own time, pace, or as many times as desired, including infinite retries and re-watching of videos; platform "walks you through"

\section{Drawbacks/Suggestions/Negative}

Adaptive platform did not indicate exactly what was done wrong, why it was wrong, nor provide the solution

Suggestion: provide detailed solutions or guidance

Access to lessons or questions limited or controlled; questions not available again until video re-watched; had to re-do questions answered correctly; could not review lessons afterwards; Platform not accessible via phone; Video was not available when working the problem (i.e., was not on the same page as the problem);

Suggestions: make platform video available when working the problem; provide only necessary information to students via the platform

Inaccurate feedback on student answers provided by the adaptive platform; platform feedback not sensitive to small differences between provided and expected answers 
Table 3.Multiple Choice Question Comparison: Four Methods.

\begin{tabular}{|c|c|c|c|c|c|c|c|}
\hline & $\begin{array}{l}\text { Blend } \\
\text { Non } \\
\text { Adaptive } \\
\text { (BNA) }\end{array}$ & $\begin{array}{c}\begin{array}{c}\text { Blend } \\
\text { Adaptive }\end{array} \\
\text { (BA) }\end{array}$ & $\begin{array}{c}\text { Flip } \\
\text { Non } \\
\text { Adaptive } \\
\text { (FNA) }\end{array}$ & $\begin{array}{c}\text { Flip } \\
\text { Adaptive } \\
\text { (FA) }\end{array}$ & \multirow[t]{2}{*}{$p$} & \multirow{2}{*}{$\begin{array}{c}\text { p adj } \\
\text { (multiple } \\
\text { comparisons) }\end{array}$} & $\begin{array}{l}\text { Effect Size } \\
\text { Cohen's d } \\
\text { (FA vs. FNA) } \\
\text { (FA vs. BA) }\end{array}$ \\
\hline & \multicolumn{4}{|c|}{ Adjusted Average Percentage \% } & & & $\begin{array}{l}\text { (FA vs. BNA) } \\
\text { (BA vs. BNA) } \\
\text { (BA vs. FNA) }\end{array}$ \\
\hline All & $\begin{array}{c}\mathbf{6 1 . 0} \\
(16.1) \\
188\end{array}$ & $\begin{array}{c}\mathbf{5 7 . 6} \\
(16.0) \\
68\end{array}$ & $\begin{array}{c}\mathbf{6 5 . 1} \\
(16.0) \\
88\end{array}$ & $\begin{array}{c}\mathbf{6 0 . 1} \\
(16.0) \\
146\end{array}$ & 0.025 & 0.05 & $\begin{array}{l}-0.32 \\
0.15 \\
-0.06 \\
-0.21 \\
-0.47 \\
0.26\end{array}$ \\
\hline URM & $\begin{array}{c}\mathbf{5 8 . 7} \\
(16.1) \\
42\end{array}$ & $\begin{array}{c}\mathbf{5 8 . 8} \\
(16.1) \\
23\end{array}$ & $\begin{array}{c}\mathbf{6 5 . 2} \\
(16.1) \\
33\end{array}$ & $\begin{array}{c}\mathbf{5 8 . 6} \\
(16.1) \\
39\end{array}$ & 0.249 & 0.498 & $\begin{array}{l}-0.41 \\
-0.01 \\
-0.01 \\
0.01 \\
-0.40 \\
0.41\end{array}$ \\
\hline
\end{tabular}

FA=Flip adaptive (Flip with adaptive)

BA=Blended adaptive (Blended with adaptive)

FNA=Flip non-adaptive (Flip without adaptive)

BNA=Blended non-adaptive (Blended without adaptive)

Effect size comparisons: when comparing each pair of teaching methods, the method after "vs." (listed above) is the reference/control category. For example, when comparing FA and FNA, FNA is the reference/control category.

This article is protected by copyright. All rights reserved. 
Table 4.Free-Response Question Comparison: Four Methods.

\begin{tabular}{|c|c|c|c|c|c|c|c|}
\hline & $\begin{array}{c}\text { Blend } \\
\text { Non } \\
\text { Adaptive } \\
\text { (BNA) }\end{array}$ & $\begin{array}{c}\text { Blend } \\
\text { Adaptive } \\
\text { (BA) }\end{array}$ & $\begin{array}{c}\text { Flip } \\
\text { Non } \\
\text { Adaptive } \\
\text { (FNA) }\end{array}$ & $\begin{array}{c}\text { Flip } \\
\text { Adaptive } \\
\text { (FA) }\end{array}$ & \multirow[t]{2}{*}{$P$} & \multirow{2}{*}{$\begin{array}{c}\text { p adj } \\
\text { (multiple } \\
\text { comparisons) }\end{array}$} & $\begin{array}{l}\text { Effect Size } \\
\text { Cohen's d } \\
\text { (FA vs. FNA) } \\
\text { (FA vs. BA) }\end{array}$ \\
\hline & \multicolumn{4}{|c|}{ Average Percentage \% } & & & $\begin{array}{l}\text { (FA vs. BNA) } \\
\text { (BA vs. BNA) } \\
\text { (BA vs. FNA) }\end{array}$ \\
\hline All & $\begin{array}{c}39.9 \\
(19.9) \\
188\end{array}$ & $\begin{array}{c}\mathbf{4 0 . 1} \\
(19.9) \\
68\end{array}$ & $\begin{array}{c}37.5 \\
(19.9) \\
88\end{array}$ & $\begin{array}{c}44.4 \\
(19.9) \\
146\end{array}$ & 0.057 & 0.114 & $\begin{array}{l}0.34 \\
0.22 \\
0.22 \\
0.01 \\
0.13 \\
-0.12\end{array}$ \\
\hline URM & $\begin{array}{c}38.4 \\
(20.6) \\
42\end{array}$ & $\begin{array}{c}\mathbf{4 6 . 8} \\
(20.6) \\
23\end{array}$ & $\begin{array}{c}37.0 \\
(20.6) \\
33\end{array}$ & $\begin{array}{c}44.8 \\
(20.6) \\
39\end{array}$ & 0.177 & 0.354 & $\begin{array}{l}0.38 \\
-0.10 \\
0.31 \\
0.41 \\
0.48 \\
-0.07\end{array}$ \\
\hline
\end{tabular}

FA=Flip adaptive (Flip with adaptive)

BA=Blended adaptive (Blended with adaptive)

FNA=Flip non-adaptive (Flip without adaptive)

BNA=Blended non-adaptive (Blended without adaptive)

Effect size comparisons: when comparing each pair of teaching methods, the method after "vs." (listed above) is the reference/control category. For example, when comparing FA and FNA, FNA is the reference/control category.

This article is protected by copyright. All rights reserved. 
Table 5.Classroom Environment Comparison: Four Methods.

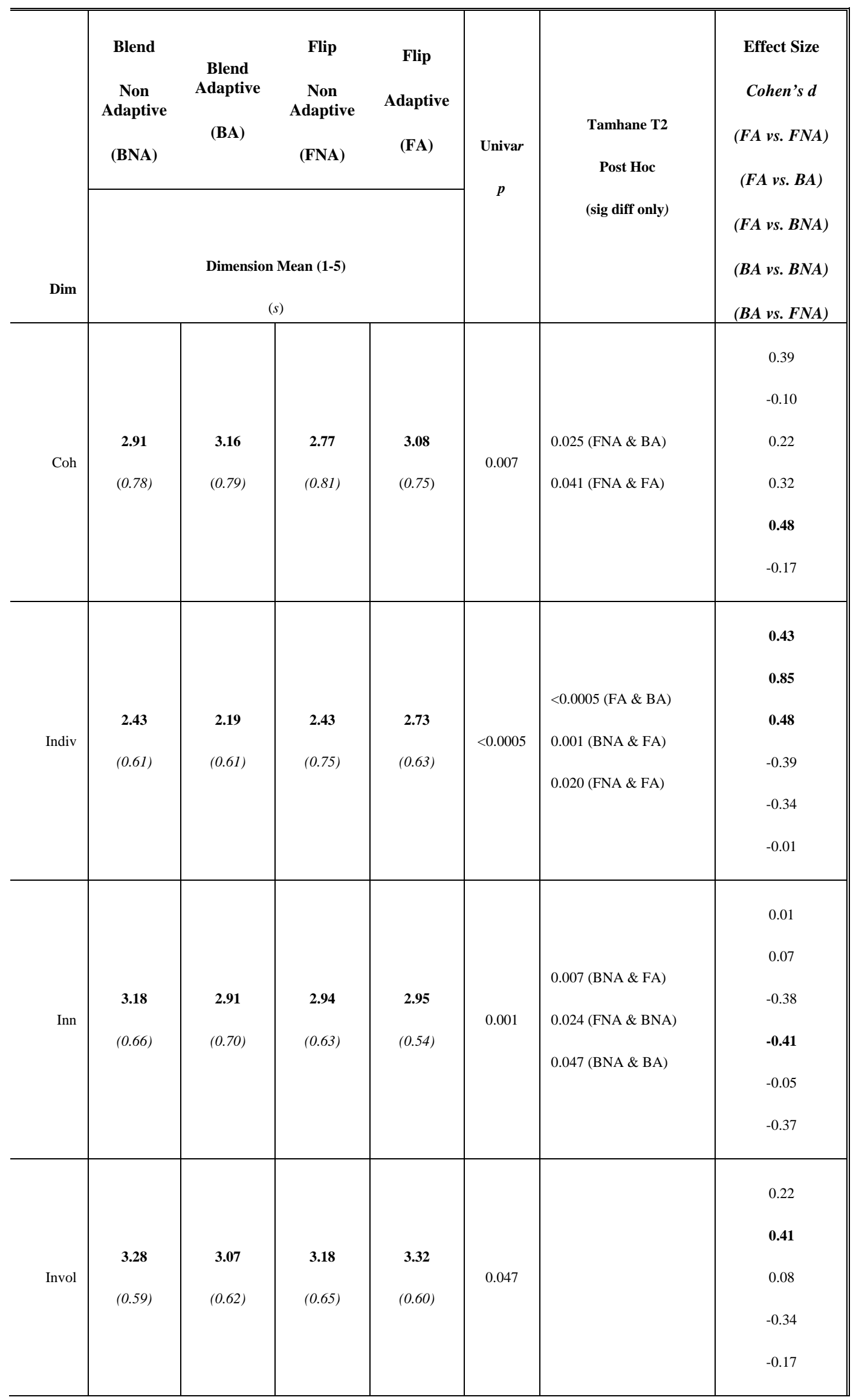

This article is protected by copyright. All rights reserved. 


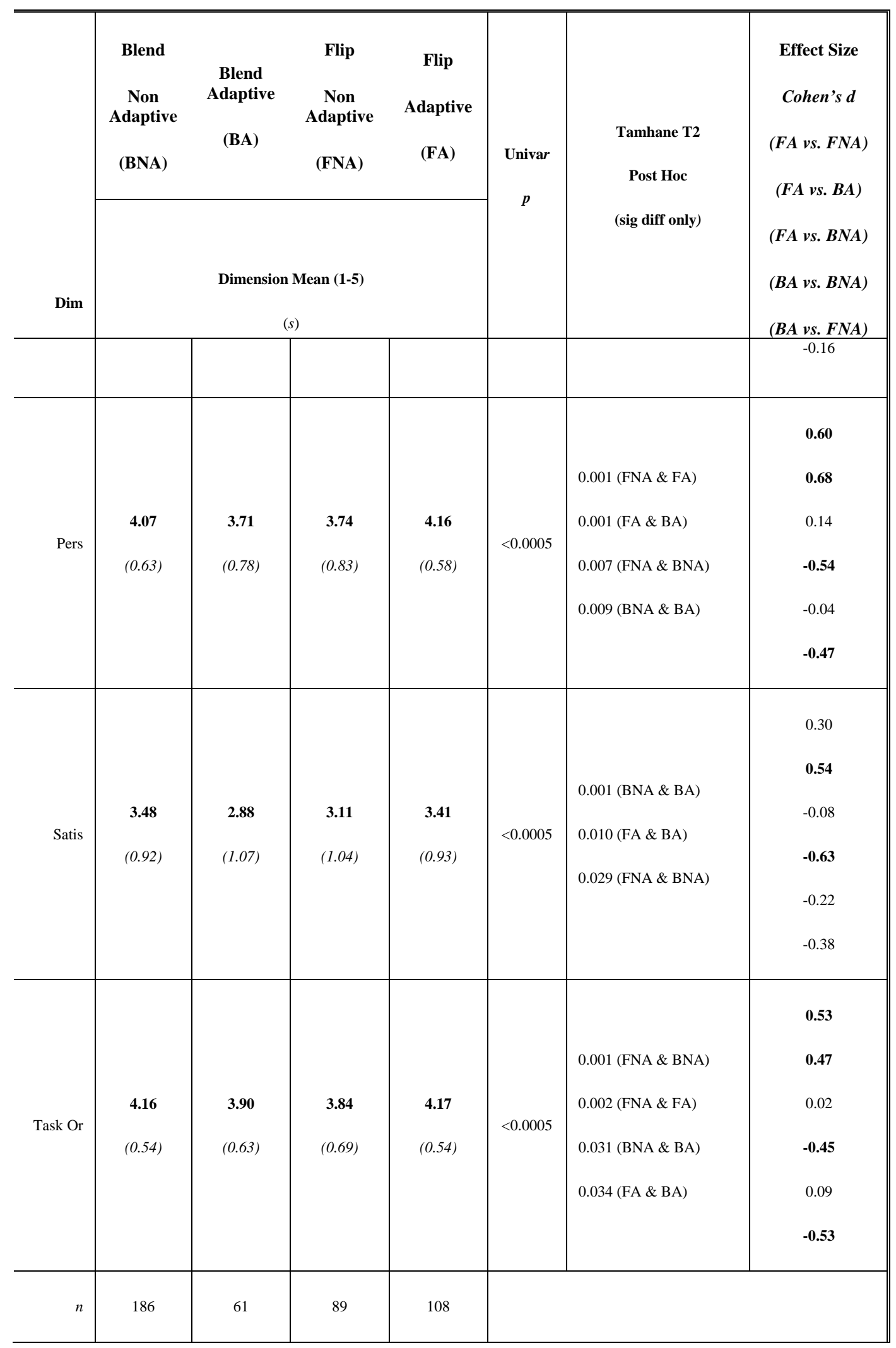

Coh = Cohesiveness (Students know \& help one another)

Indiv = Individualization (Students treated individually/differentially or allowed to make decisions)

Inn = Innovation (Novel class activities, teaching techniques, or assignments)

Invol = Involvement (Active student participation in class activities)

This article is protected by copyright. All rights reserved. 
Pers $=$ Personalization (Interaction $\mathrm{w} /$ instructor; concern for student welfare)

Satis $=$ Satisfaction $($ Enjoyment of classes $)$

Task Or $=$ Task orientation (Organization and clarity of class activities)

BNA=Blended non-adaptive; BA=Blended adaptive; FNA=Flipped non-adaptive; FA=Flipped adaptive

Effect size comparisons: when comparing each pair of teaching methods, the method after "vs." (listed above) is the reference/control category. For example, when comparing FA and FNA, FNA is the reference/control category.

Table 6. Focus Group Q1: AELP Learning Impact: Positive/Negative by Method

\begin{tabular}{l|c|c|c|c|c|c|c}
\hline $\begin{array}{c}\text { Instructional } \\
\text { Method }\end{array}$ & $\begin{array}{c}\text { Total } \\
\text { Participants }\end{array}$ & Positive & $\begin{array}{c}\text { \% } \\
\text { Positive }\end{array}$ & Negative & $\begin{array}{c}\% \\
\text { Negative }\end{array}$ & Mixed & $\begin{array}{c}\% \\
\text { Mixed }\end{array}$ \\
\hline Blended & 10 & 6 & $\mathbf{6 0 \%}$ & 1 & $10 \%$ & 2 & $20 \%$ \\
\hline Flipped & 20 & 7 & $\mathbf{3 5 \%}$ & 5 & $25 \%$ & 7 & $35 \%$ \\
\hline
\end{tabular}

Table 7: Focus Group Q1: AELP Learning Impact: Positive/Negative by Demographic

\begin{tabular}{l|c|c|c|c|c|c|c}
\hline $\begin{array}{c}\text { Demographic } \\
\text { Group }\end{array}$ & $\begin{array}{c}\text { Total } \\
\text { Participants }\end{array}$ & Positive & $\begin{array}{c}\text { \% } \\
\text { Positive }\end{array}$ & Negative & $\begin{array}{c}\% \\
\text { Negative }\end{array}$ & Mixed & $\begin{array}{c}\% \\
\text { Mixed }\end{array}$ \\
\hline White males & 16 & 6 & $\mathbf{3 8 \%}$ & 4 & $25 \%$ & 4 & $25 \%$ \\
\hline $\begin{array}{l}\text { Other than } \\
\text { White males }\end{array}$ & 14 & 7 & $\mathbf{5 0 \%}$ & 2 & $14 \%$ & 5 & $36 \%$ \\
\hline
\end{tabular}

Table 8. Content Analysis of Focus Group Q1 on AELP Learning Impact

\begin{tabular}{l|c|c|c|c}
\hline Content Analysis: & $\begin{array}{c}\text { \% of White } \\
\text { Male } \\
\text { Participants }\end{array}$ & $\begin{array}{c}\text { \% of Other- } \\
\text { than-White- } \\
\text { Male } \\
\text { Participants }\end{array}$ & $\begin{array}{c}\% \text { of } \\
\text { Blended } \\
\text { Participants }\end{array}$ & $\begin{array}{c}\text { Flipped } \\
\text { Participants }\end{array}$ \\
\hline MAT PREP & $50 \%$ & $79 \%$ & $70 \%$ & $60 \%$ \\
(lecture preparation, understanding) & & & \\
\hline
\end{tabular}

This article is protected by copyright. All rights reserved. 


\begin{tabular}{|c|c|c|c|c|}
\hline $\begin{array}{l}\text { Content Analysis: } \\
\text { AELP Learning Impact }\end{array}$ & $\begin{array}{l}\% \text { of White } \\
\text { Male } \\
\text { Participants }\end{array}$ & $\begin{array}{l}\text { \% of Other- } \\
\text { than-White- } \\
\text { Male } \\
\text { Participants }\end{array}$ & $\begin{array}{c}\text { \% of } \\
\text { Blended } \\
\text { Participants }\end{array}$ & $\begin{array}{c}\% \text { of } \\
\text { Flipped } \\
\text { Participants }\end{array}$ \\
\hline $\begin{array}{l}\text { CONVENIENCE } \\
\text { (one online location, re-watch videos, re-do questions) }\end{array}$ & $25 \%$ & $29 \%$ & $40 \%$ & $20 \%$ \\
\hline $\begin{array}{l}\text { QUIZ QUES } \\
\text { (quiz questions alongside lecture) }\end{array}$ & $13 \%$ & $36 \%$ & $10 \%$ & $30 \%$ \\
\hline $\begin{array}{l}\text { NOT CLEAR } \\
\text { (adaptive platform not clear about incorrect responses, } \\
\text { solution not provided) }\end{array}$ & $25 \%$ & $0 \%$ & $0 \%$ & $20 \%$ \\
\hline $\begin{array}{l}\text { ACCESS } \\
\text { (access to lessons/questions limited, questions not available } \\
\text { until video re-watched, re-doing of correct work) }\end{array}$ & $13 \%$ & $14 \%$ & $0 \%$ & $20 \%$ \\
\hline $\begin{array}{l}\text { WORKLOAD } \\
\text { (high workload, time-consuming, unnecessary or repetitive } \\
\text { work) }\end{array}$ & $13 \%$ & $14 \%$ & $10 \%$ & $15 \%$ \\
\hline $\begin{array}{l}\text { INACC FEED } \\
\text { (adaptive platform provides inaccurate feedback, platform } \\
\text { not sensitive to small differences) }\end{array}$ & $6 \%$ & $7 \%$ & $10 \%$ & $5 \%$ \\
\hline
\end{tabular}

Table 9. Focus Group Q2: AELP Satisfaction: Positive/Negative by Method

\begin{tabular}{l|c|c|c|c|c|c|c}
\hline $\begin{array}{c}\text { Instructional } \\
\text { Method }\end{array}$ & $\begin{array}{c}\text { Total } \\
\text { Participants }\end{array}$ & Positive & $\begin{array}{c}\text { \% } \\
\text { Positive }\end{array}$ & Negative & $\begin{array}{c}\% \\
\text { Negative }\end{array}$ & Mixed & $\begin{array}{c}\% \\
\text { Mixed }\end{array}$ \\
\hline Blended & 10 & 2 & $\mathbf{2 0 \%}$ & 1 & $10 \%$ & 7 & $70 \%$ \\
\hline Flipped & 20 & 6 & $\mathbf{3 0 \%}$ & 7 & $35 \%$ & 6 & $30 \%$ \\
\hline
\end{tabular}

This article is protected by copyright. All rights reserved. 
Table 10. Focus Group Q2: AELP Satisfaction: Positive/Negative by Demographic

\begin{tabular}{l|c|c|c|c|c|c|c}
\hline $\begin{array}{c}\text { Demographic } \\
\text { Group }\end{array}$ & $\begin{array}{c}\text { Total } \\
\text { Participants }\end{array}$ & Positive & $\begin{array}{c}\text { \% } \\
\text { Positive }\end{array}$ & Negative & $\begin{array}{c}\% \\
\text { Negative }\end{array}$ & Mixed & $\begin{array}{c}\% \\
\text { Mixed }\end{array}$ \\
\hline White males & 16 & 2 & $\mathbf{1 3 \%}$ & 5 & $31 \%$ & 9 & $56 \%$ \\
\hline $\begin{array}{l}\text { Other than } \\
\text { White males }\end{array}$ & 14 & 6 & $\mathbf{4 3 \%}$ & 3 & $21 \%$ & 4 & $29 \%$ \\
\hline
\end{tabular}

Table 11. Content Analysis of Focus Group Q2 on AELP Satisfaction

\begin{tabular}{|c|c|c|c|c|}
\hline $\begin{array}{l}\text { Content Analysis: } \\
\text { AELP Satisfaction }\end{array}$ & $\begin{array}{c}\text { \% of } \\
\text { White } \\
\text { Male } \\
\text { Particip } \\
\text { ants }\end{array}$ & $\begin{array}{c}\% \text { of } \\
\text { Other- } \\
\text { than- } \\
\text { White- } \\
\text { Male } \\
\text { Particip } \\
\text { ants }\end{array}$ & $\begin{array}{c}\% \text { of } \\
\text { Blende } \\
\text { d } \\
\text { Particip } \\
\text { ants }\end{array}$ & $\begin{array}{l}\% \text { of } \\
\text { Flipped } \\
\text { Particip } \\
\text { ants }\end{array}$ \\
\hline $\begin{array}{l}\text { MAT PREP } \\
\text { (lecture preparation, understanding) }\end{array}$ & $19 \%$ & $0 \%$ & $0 \%$ & $15 \%$ \\
\hline $\begin{array}{l}\text { CONVENIENCE } \\
\text { (one online location, re-watch videos, re-do questions) }\end{array}$ & $19 \%$ & $29 \%$ & $10 \%$ & $30 \%$ \\
\hline $\begin{array}{l}\text { QUIZ QUES } \\
\text { (quiz questions alongside lecture) }\end{array}$ & $13 \%$ & $14 \%$ & $0 \%$ & $20 \%$ \\
\hline $\begin{array}{l}\text { NOT CLEAR } \\
\text { (adaptive platform not clear about incorrect responses, solution not } \\
\text { provided) }\end{array}$ & $31 \%$ & $21 \%$ & $30 \%$ & $25 \%$ \\
\hline $\begin{array}{l}\text { ACCESS } \\
\text { (access to lessons/questions limited, questions not available until video } \\
\text { re-watched, re-doing of correct work) }\end{array}$ & $63 \%$ & $0 \%$ & $20 \%$ & $40 \%$ \\
\hline WORKLOAD & $0 \%$ & $14 \%$ & $10 \%$ & $5 \%$ \\
\hline
\end{tabular}

This article is protected by copyright. All rights reserved. 


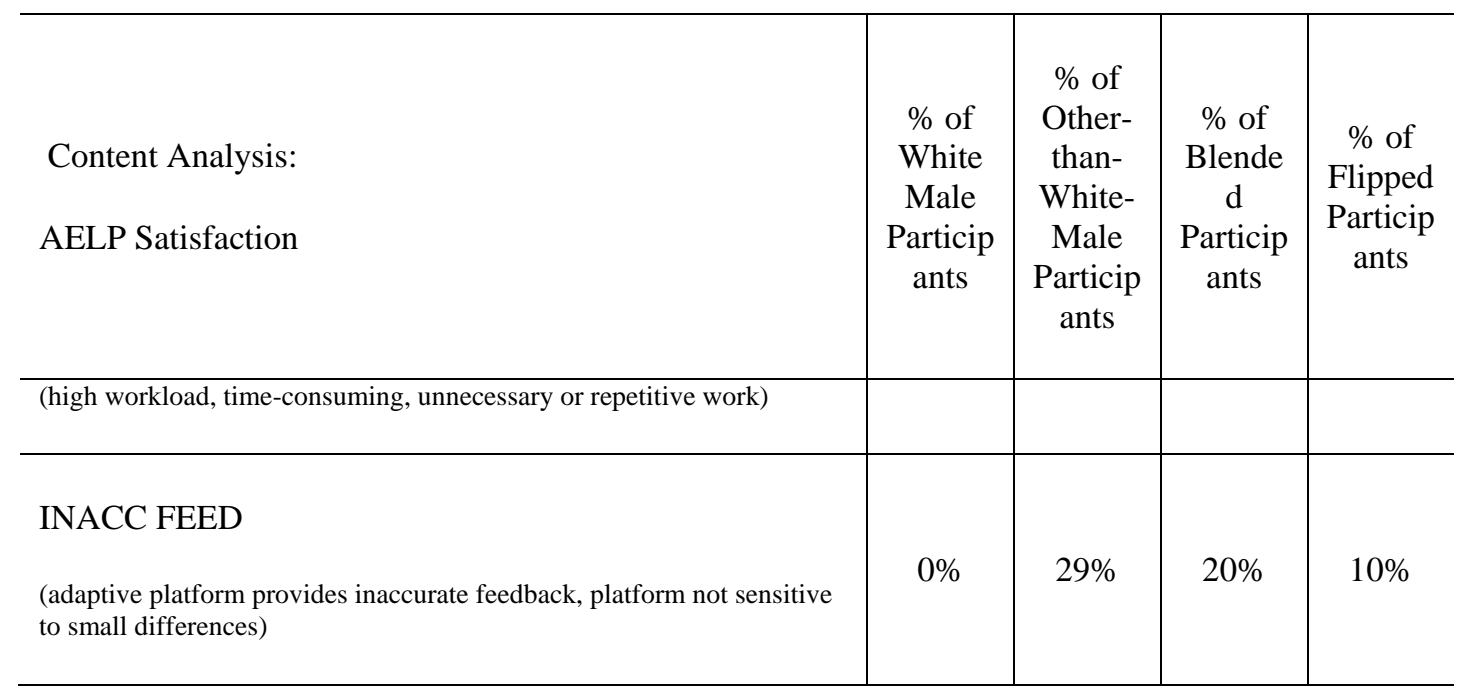

Table 12. Focus Group Q3: AELP \& Engagement: Positive/Negative by Method

\begin{tabular}{l|c|c|c|c|c|c|c}
\hline $\begin{array}{c}\text { Instructional } \\
\text { Method }\end{array}$ & $\begin{array}{c}\text { Total } \\
\text { Participants }\end{array}$ & Positive & $\begin{array}{c}\text { \% } \\
\text { Positive }\end{array}$ & Negative & $\begin{array}{c}\% \\
\text { Negative }\end{array}$ & Mixed & $\begin{array}{c}\% \\
\text { Mixed }\end{array}$ \\
\hline Blended & 10 & 1 & $\mathbf{1 0 \%}$ & 2 & $20 \%$ & 4 & $40 \%$ \\
\hline Flipped & 20 & 11 & $\mathbf{5 5 \%}$ & 4 & $20 \%$ & 1 & $5 \%$ \\
\hline
\end{tabular}

Table 13. Focus Group Q3: AELP \& Engagement: Positive/Negative by Demographic

\begin{tabular}{l|c|c|c|c|c|c|c}
\hline $\begin{array}{c}\text { Demographic } \\
\text { Group }\end{array}$ & $\begin{array}{c}\text { Total } \\
\text { Participants }\end{array}$ & Positive & $\begin{array}{c}\% \\
\text { Positive }\end{array}$ & Negative & $\begin{array}{c}\% \\
\text { Negative }\end{array}$ & Mixed & $\begin{array}{c}\% \\
\text { Mixed }\end{array}$ \\
\hline White males & 16 & 7 & $\mathbf{4 4 \%}$ & 3 & $19 \%$ & 1 & $6 \%$ \\
\hline $\begin{array}{l}\text { Other than } \\
\text { White males }\end{array}$ & 14 & 5 & $\mathbf{3 6 \%}$ & 3 & $21 \%$ & 4 & $29 \%$ \\
\hline
\end{tabular}

This article is protected by copyright. All rights reserved. 
Table 14. Content Analysis of Focus Group Q3 on AELP \& Engagement

\begin{tabular}{|c|c|c|c|c|}
\hline $\begin{array}{l}\text { Content Analysis: } \\
\text { AELP \& Engagement }\end{array}$ & $\begin{array}{l}\% \text { of White } \\
\text { Male } \\
\text { Participants }\end{array}$ & $\begin{array}{l}\text { \% of } \\
\text { Other-than- } \\
\text { White- } \\
\text { Male } \\
\text { Participants }\end{array}$ & $\begin{array}{c}\% \text { of } \\
\text { Blended } \\
\text { Participants }\end{array}$ & $\begin{array}{c}\% \text { of Flipped } \\
\text { Participants }\end{array}$ \\
\hline $\begin{array}{l}\text { MAT PREP } \\
\text { (lecture preparation, understanding) }\end{array}$ & $44 \%$ & $7 \%$ & $10 \%$ & $35 \%$ \\
\hline $\begin{array}{l}\text { CONVENIENCE } \\
\text { (one online location, re-watch videos, re-do questions) }\end{array}$ & $0 \%$ & $29 \%$ & $0 \%$ & $20 \%$ \\
\hline $\begin{array}{l}\text { QUIZ QUES } \\
\text { (quiz questions alongside lecture) }\end{array}$ & $0 \%$ & $14 \%$ & $0 \%$ & $10 \%$ \\
\hline $\begin{array}{l}\text { NOT CLEAR } \\
\text { (adaptive platform not clear about incorrect responses, } \\
\text { solution not provided) }\end{array}$ & $0 \%$ & $0 \%$ & $0 \%$ & $0 \%$ \\
\hline $\begin{array}{l}\text { ACCESS } \\
\text { (access to lessons/questions limited, questions not available } \\
\text { until video re-watched, re-doing of correct work) }\end{array}$ & $6 \%$ & $0 \%$ & $0 \%$ & $5 \%$ \\
\hline $\begin{array}{l}\text { WORKLOAD } \\
\text { (high workload, time-consuming, unnecessary or repetitive } \\
\text { work) }\end{array}$ & $0 \%$ & $14 \%$ & $20 \%$ & $0 \%$ \\
\hline $\begin{array}{l}\text { INACC FEED } \\
\text { (adaptive platform provides inaccurate feedback, platform } \\
\text { not sensitive to small differences) }\end{array}$ & $0 \%$ & $0 \%$ & $0 \%$ & $0 \%$ \\
\hline
\end{tabular}

Table 15. Focus Group Q4: Compare \& Contrast: Positive/Negative by Method

\begin{tabular}{c|c|c|c|c|c|c|c}
\hline $\begin{array}{c}\text { Instructional } \\
\text { Method }\end{array}$ & $\begin{array}{c}\text { Total } \\
\text { Participants }\end{array}$ & $\begin{array}{c}\text { AELP } \\
\text { Better }\end{array}$ & $\begin{array}{c}\text { \% } \\
\text { AELP } \\
\text { Better }\end{array}$ & $\begin{array}{c}\text { AELP } \\
\text { Not } \\
\text { Better }\end{array}$ & $\begin{array}{c}\text { \% AELP } \\
\text { Not } \\
\text { Better }\end{array}$ & $\begin{array}{c}\text { No } \\
\text { Diff }\end{array}$ & $\begin{array}{c}\text { \% No } \\
\text { Diff }\end{array}$ \\
\hline
\end{tabular}

This article is protected by copyright. All rights reserved. 


\begin{tabular}{l|c|c|c|c|c|c|c} 
Blended & 10 & 3 & $\mathbf{3 0} \%$ & 3 & $30 \%$ & 3 & $30 \%$ \\
\hline Flipped & 20 & 10 & $\mathbf{5 0 \%}$ & 1 & $5 \%$ & 4 & $20 \%$ \\
\hline
\end{tabular}

Table 16. Focus Group Q4: Compare \& Contrast: Positive/Negative by Demographic

\begin{tabular}{l|c|c|c|c|c|c|c}
\hline $\begin{array}{c}\text { Demographic } \\
\text { Group }\end{array}$ & $\begin{array}{c}\text { Total } \\
\text { Participants }\end{array}$ & $\begin{array}{c}\text { AELP } \\
\text { Better }\end{array}$ & $\begin{array}{c}\text { \% } \\
\text { AELP } \\
\text { Better }\end{array}$ & $\begin{array}{c}\text { AELP } \\
\text { Not } \\
\text { Better }\end{array}$ & $\begin{array}{c}\text { \% AELP } \\
\text { Not } \\
\text { Better }\end{array}$ & $\begin{array}{c}\text { No } \\
\text { Diff }\end{array}$ & $\begin{array}{c}\% \text { No } \\
\text { Diff }\end{array}$ \\
\hline White males & 16 & 7 & $\mathbf{4 4 \%}$ & 0 & $0 \%$ & 4 & $25 \%$ \\
\hline $\begin{array}{l}\text { Other than } \\
\text { White males }\end{array}$ & 14 & 6 & $\mathbf{4 3 \%}$ & 4 & $29 \%$ & 3 & $21 \%$ \\
\hline
\end{tabular}

Table 17. Content Analysis of Focus Group Q4 on Compare \& Contrast

\begin{tabular}{l|c|c|c|c}
\hline Content Analysis: & $\begin{array}{c}\text { \% of White } \\
\text { Male } \\
\text { Participants } \\
\text { Compare \& Contrast }\end{array}$ & $\begin{array}{c}\text { \% of Other- } \\
\text { than-White- } \\
\text { Male } \\
\text { Participants }\end{array}$ & $\begin{array}{c}\text { Blended of } \\
\text { Participants }\end{array}$ & $\begin{array}{c}\text { Flipped of } \\
\text { Participants }\end{array}$ \\
\hline MAT PREP & $50 \%$ & $29 \%$ & $30 \%$ & $45 \%$ \\
$\begin{array}{l}\text { (lecture preparation, understanding) } \\
\text { CONVENIENCE }\end{array}$ & $31 \%$ & $21 \%$ & $20 \%$ & $30 \%$ \\
$\begin{array}{l}\text { (one online location, re-watch videos, re-do questions) } \\
\text { QUIZ QUES }\end{array}$ & $0 \%$ & $21 \%$ & $0 \%$ & $15 \%$ \\
\hline $\begin{array}{l}\text { (quiz questions alongside lecture) } \\
\text { (adaptive platform not clear about incorrect responses, }\end{array}$ & $6 \%$ & $0 \%$ & $5 \%$ \\
\hline
\end{tabular}

This article is protected by copyright. All rights reserved. 


\begin{tabular}{l|c|c|c|c}
\hline \multicolumn{1}{c|}{ Content Analysis: } & $\begin{array}{c}\text { \% of White } \\
\text { Male } \\
\text { Participants }\end{array}$ & $\begin{array}{c}\text { \% of Other- } \\
\text { than-White- } \\
\text { Male } \\
\text { Participants }\end{array}$ & $\begin{array}{c}\% \text { of } \\
\text { Blended } \\
\text { Participants }\end{array}$ & $\begin{array}{c}\text { F of } \\
\text { Flipped } \\
\text { Participants }\end{array}$ \\
\hline $\begin{array}{l}\text { ACCESS } \\
\text { (access to lessons/questions limited, questions not } \\
\text { available until video re-watched, re-doing of correct work) }\end{array}$ & $6 \%$ & $0 \%$ & $0 \%$ & $5 \%$ \\
\hline $\begin{array}{l}\text { WORKLOAD } \\
\text { (high workload, time-consuming, unnecessary or } \\
\text { repetitive work) }\end{array}$ & $0 \%$ & $29 \%$ & $40 \%$ & $0 \%$ \\
\hline $\begin{array}{l}\text { INACC FEED } \\
\text { (adaptive platform provides inaccurate feedback, platform } \\
\text { not sensitive to small differences) }\end{array}$ & $0 \%$ & $0 \%$ & $0 \%$ & $0 \%$ \\
\hline
\end{tabular}

This article is protected by copyright. All rights reserved. 